\title{
Exploring the Impact of Religiosity and Socioeconomic Factors on Perceived Ideal Timing of Marriage in Young Adults
}

\author{
Jenifer N. Fuller ${ }^{\mathrm{a}}$, Ami M. H. Frost ${ }^{\mathrm{b}}$, and Brandon K. Burr ${ }^{\mathrm{a}}$
}

\begin{abstract}
In light of rising averages in the age of first marriage for men and women, as well as changes in attitudes regarding marriage and family life in young adults, the study of marital timing has received increased attention in recent years. Marital timing has been known to be associated with various aspects of marital satisfaction and stability, yet most research has focused on limited variables to assess perceptions of the ideal timing of marriage. This study explored the association of demographic, current and background socioeconomic (SES) factors, and religiosity with various measures of perceived ideal marital timing in a sample of 385 unmarried young adults. Overall, results indicate that religiosity and ethnicity have an impact on perceived ideal age and timing of marriage. Also, less pronounced associations were found between SES factors and perceived marital timing. Implications and future directions for family practitioners and researchers are discussed.
\end{abstract}

Keywords: young adults, socioeconomic status, religiosity, marital timing, marital age

The topic of marital timing has generated increased interest in popular media and scientific study over recent years. Marital timing has been one of the most dramatic areas of discussion as part of a larger wave of changes that include multiple shifts in marriage and family life in the United States over the past 60 years. For instance, some reports show that although many unmarried young adults see marriage as a good possibility (Cherlin, 2009; Scott, Schelar, Manlove, \& Cui, 2009), the average age at first marriage continues to rise for men and women, and the percentage of married adults has reached an all-time low (Cohn, Passel, Wang, \& Livingston, 2011; Copen, Daniels, Vespa, \& Mosher, 2012; Krogstad, 2014). Some suggest that these trends are related to changing attitudes and behaviors in "emerging adults" (those approximately $18-25$ in age), who often spend their late teens and 20s exploring different experiences and more gradually forming long-term adult roles in terms of career choices and romantic relationships (Arnett, 2004, 2007).

Marital timing remains an important area of investigation as age at marriage has been consistently identified as a risk factor for divorce, particularly for those marrying before age 20 (Amato, 2010; DeGenova, Stinnett, \& Stinnett, 2011). Additionally, cohabitation rates are another important area to consider when investigating martial timing in young adults. As noted above, marriage rates have dropped, but cohabitation rates have risen dramatically (Kuperberg, 2014). According to recent reports, $48 \%$ of women ages 15-44 currently live with a cohabiting partner (Copen, Daniels, \& Mosher, 2013), and by age 25 nearly half of young adults have spent some time in a cohabiting relationship (Payne, 2011). Kuperberg (2014) found that younger partner age when establishing a cohabiting union was associated with higher divorce rates for those cohabiting couples who went on to marry. Thus, timing represents an important area of consideration when examining various romantic relationships, particularly over young adulthood, and, as described above, may have an impact on both marital quality and stability.

Because marital timing plays an important role in relationships, learning more about how attitudes toward marital timing are shaped, particularly in young adults where these attitudes appear to be changing, represents an important endeavor in order to more effectively support healthy relationship development. Much of the previous study of marital timing has not expanded beyond age as the primary area of investigation, and to our knowledge no previous work exists examining how various perceptions of marital timing are potentially shaped in a young adult sample. This study adds to this body of literature by exploring how various aspects of marital timing are potentially influenced by several socioeconomic and demographic factors (e.g., individual income and education, socioeconomic status of family of origin, parents' marital status), as well as personal beliefs (i.e., religiosity).

\section{Factors Influencing Marital Timing}

Existing literature on marital timing provides some insight into the various factors that influence the decision and the time to marry. For example, MacInnes (2011) found that individuals were more likely to experience a first marriage at a younger age if they had certain characteristics, which may include having poorly educated parents, being more religious, being white, being a woman, and being an individual with a high school diploma as the highest level of education earned. Also, as mentioned, such demographic and socioeconomic factors are important to consider, as they often have a bearing on marital satisfaction and marital outcomes (Amato, 2010). Literature addressing influencing factors on marital timing in this study is explored in further detail below.

\section{Age and Marital Timing}

Various studies dating back to the 1970s support the connection between younger age at marriage and higher divorce rates, with effects beginning to plateau when marriage takes place during the mid-late 20s (e.g., Booth \& Edwards, 1985; Heaton, 1991; Lee, 1977; Raley \& Bumpass, 2003). Other research has found that those who married between the 
ages of 22 and 25 reported greater marital quality than those who married later (Glenn, Uecker, \& Love, 2010). Thus, marital age, at least into the mid-20s, has shown to be protective against divorce.

Also, as mentioned previously, increased likelihood of divorce has been linked to age at cohabitation; the younger individuals are when they begin cohabitating, when they go on to marry, the more likely they are to divorce (Kuperberg, 2014). Kuperberg notes that those who enter cohabiting relationships at younger ages and subsequently marry may be more likely to divorce "because they were too young and unprepared to select and settle down with a partner at the age they began their coresidence" (p. 368). In this manner, cohabitation at an early age may be associated with inadequate role preparation and mate selection practices that can lead to relationship dissolution for those who subsequently marry.

What age do young adults perceive as ideal to marry? Carroll and colleagues (2007) explored the ideal age to marry in a sample of young adults. Both young adult men and young adult women indicated about 25 years old as an ideal age for marriage. This ideal age remained consistent among men across the different age groups within the sample. For women, however, ideal age ranged from 24.4 years old among 18 - and 19 -year-olds to 26.8 years old for 24-26-year-olds.

\section{Demographic Factors, Socioeconomic Factors, and Marital Timing}

Several different demographic and socioeconomic factors have been found to influence marital timing. In terms of race-ethnic differences, Hispanics are the most likely to marry young, followed by Whites, Asians, and Blacks (Glick, Ruf, White, \& Goldscheider, 2006; Teachman, Polonko, \& Leigh, 1987; Teachman, Tedrow, \& Crowder, 2000; Uecker \& Stokes, 2008). Greater educational achievement has been found to delay marriage in black men (Oppenheimer, Kalmijn, \& Lim, 1997; Koball, 1998). The same correlation is found for black and white women, although the marriage rates for these women are forecasted to be higher despite the later entry into marriage (Goldstein \& Kenney, 2001).

Family background and socioeconomic factors have also been known to influence marital timing. Beal and Crockett (2012) found that adolescent expectations of appropriate timing to enter into adult roles, including marriage, were affected by parental demographic factors, such as educational attainment and occupation. Other results show that those whose parents have higher levels of educational achievement and greater financial means are less likely to marry young (Axinn \& Thornton, 1992; Uecker \& Stokes, 2008).

Relationship status, in terms of one's parents and one's current situation, also may influence marital timing. Keith and Finlay (1988) found that parental divorce was associated with earlier age at marriage for both sons and daughters. Other findings have shown that children whose parents divorce are more likely to experience divorce in their own marriages (e.g., Amato, 1996), thus attitudes toward marriage and marital timing may be different for those who experience a parental divorce as opposed to those who do not.

Also, current relationship status may have an influence on marital timing. The rise in cohabitation, in particular among young adults, may be associated with postponing marriage. Some see cohabitation as a substitute for early marriage and may be more likely to delay marriage (Raley, 2000). Yet Uecker and Stokes (2008) found that young adults who cohabit are more likely to enter marriage early. They note that those who cohabit are more likely to marry at younger ages than those who are single, since cohabitation may be viewed as a precursor to marriage. Thus those in cohabiting relationships may see marital timing differently than those who are dating (not cohabiting) and those who are single.

\section{Religiosity and Marital Timing}

Religiosity has been associated with decision making in several important areas, including work-family tradeoffs, choice of occupation, place of residence, how many children to have, and decisions surrounding marriage (Ammons \& Edgell, 2007; Sigalow, Shain, \& Bergey, 2012). Sigalow et al. found that, when compared to those who reported lower religion/faith commitment, those with higher commitment were three times more likely to state that religion influenced their marriage decision on whether to marry and whom to marry.

Religion has also been shown to play a significant role in the timing of marriage. Carroll, Hill, Vitas, and Willoughby (2012) found that a significant predictor of young adults' ideal marital timing is religiosity, since more religious young adults place more importance on marriage. In addition, research has shown that having any sort of Christian religious affiliation is associated with earlier marital timing for women when compared to women with no religious affiliation (Ellison, Burdette, \& Glenn, 2011; Carroll et al.). Uecker and Stokes (2008) also found that higher internal religious commitment lead to earlier marriage.

Further research has indicated that education and family structure may moderate the influence of religiosity on marital timing. Ellison and colleagues (2011) found that women who came from a two-parent family possessed the strongest predictors of having marriage as a short-term goal. They noted that college women from two-parent families tend to be more religiously active and more inclined to value and anticipate marriage than other college women; moreover, college women from two-parent families are twice as likely to have marriage as a short-term goal compared to women from other family structures.

In addition, women from two-parent families have their parents as a model for the values of sanctity and permanence of marriage. Ellison et al. (2011) asserted that religiosity and religious attendance are strong predictors of marrying early in that religiosity is related to the importance of marriage as a goal and timing of marriage expectations. Also, research shows that, as compared to individuals with less than a high school education, individuals with more than a high school education had twice the likelihood of reporting that their marital decision-making was influenced by religious factors (Sigalow et al., 2012).

\section{Theoretical Framework: Marital Horizons}

Developed by Carroll et al. in 2007, the marital horizon theory of emerging adulthood provides a conceptual framework for the present study. Carroll et al. identified three 
specific yet connected components that contribute to a person's outlook on marriage in their future: the relative importance of marriage, ideal age for marriage, and the criteria for considering themselves ready for marriage. Moreover, marital horizon theory argues that these three components can influence the course of emerging adults' paths into adulthood. While emerging adults expressed a general agreement that marriage is an important part of their futures (Carroll et al.), the varying levels of priority for and attitudes toward marriage have been shown to play a compelling role in the behaviors of young adults, including sexual behaviors and risk taking, as well as career and educational endeavors.

Much of the research that has utilized marital horizon theory since its inception has focused on understanding the behaviors of emerging adults and how those behaviors affect individual development and family formation patterns (e.g., Carroll et al., 2007; Carroll et al., 2009; Willoughby, 2012). In essence, marital horizon theory and subsequent research have suggested that relative importance of marriage, ideal marital timing, and marriage readiness in emerging adults has significant impacts on young adult behavior and their trajectories.

The marital timing component of marital horizon theory has been described as having the greatest salience predicting young adult behavior (Willoughby, Carroll, Vitas, \& Hill 2012). Research studying the marital timing aspect has shown that marital timing can be predictive of risk-taking behaviors. For example, Carroll et al. (2007) found that the desire to prolong emerging adulthood (push marriage into the distant future) was associated with higher substance use and increased sexual permissiveness in a sample of young adult men and women. Further research indicates that the marital timing aspect is influenced by one's background. Willoughby et al. (2012) found that parents' attitudes toward ideal marital age had a direct impact on the ideal age to marry of their children.

Overall, identifying the salient factors in marital attitude formation, combined with the established research on how these marital attitudes affect behavior and young adult trajectories, can provide researchers with a deeper understanding of the emerging adulthood stage of the family life cycle. The present study seeks to further understand the variables that influence the formation of marital attitudes in emerging adults. Focusing primarily on the marital timing and marriage readiness components of marital horizon theory, we seek to understand how age, socioeconomic status, and religiosity affect young adult's perceptions of marriage. In addition, we provide a more multifaceted conceptualization of ideal marital timing, including ideal age, ideal time of life, age considered too young to marry, and age people become set in their ways.

\section{The Current Study}

In the majority of existing investigation into marital timing has focused solely on marital age, this study adds to the literature by exploring how socioeconomic, demographic, and personal belief factors are associated with various aspects of marital timing in young adults. This study utilizes three dependent variables to more broadly conceptualize marital age. These variables are: age considered too young to marry, ideal age to marry, and age people become set in their ways and may have trouble in a marital relationship. Some work based on the coordinated development thesis postulates that those who spend early adulthood single and living alone become set in their ways and may experience difficulty adjusting to marriage (Regnerus, 2009). Thus, we sought to explore this largely under investigated area (Glenn et al., 2010) as a component of marital timing in this study. We also include a variable assessing the ideal time to marry. In addition to age, education level has been widely shown to be a risk factor for divorce (Amato, 2010; Holman, 2001), thus the perceived timing of marriage (whether before college, after college, etc.) is an important area to consider when assessing marital timing.

Marital horizon theory has been shown to be informative in understanding the attitudes and behaviors of emerging adults (Carroll et al., 2009; Willoughby, 2012). Since attitudes toward marriage and marrying behavior have changed, particularly among young adults, continuing to assess how marital timing attitudes, intentions, and behaviors are influenced will be of ongoing importance. In this study we assess how the previously described attitudes toward marital timing are potentially influenced by a number of factors.

Four general research questions were posed for this study:

- Research Question One: How are demographics (age, sex, and ethnicity), parents' relationship status, family background SES, current SES, current relationship status, and religiosity associated with the age one perceives as too young to get married?

- Research Question Two: How are demographics (age, sex, and ethnicity), parents' relationship status, family background SES, current SES, current relationship status, and religiosity associated with the age one perceives as ideal to get married?

- Research Question Three: How are demographics (age, sex, and ethnicity), parents' relationship status, family background SES, current SES, current relationship status, and religiosity associated with the timing one perceives as ideal to get married?

- Research Question Four: How are demographics (age, sex, ethnicity), parents' relationship status, family background SES, current SES, current relationship status, and religiosity associated with the age one perceives that people start getting "set in their ways" and may have more difficulty in marriage?

\section{Methods}

Sample

To more specifically investigate attitudes toward marital timing in young adults, those ages 25 and younger and unmarried were selected from a larger sample. The final sample was composed of 385 individuals. Of these individuals, $84.6 \%$ were female and $15.4 \%$ were male. Age of the participants ranged from 18 to 25 , with the mean falling in the $18-20$ age group $(S D=.71)$. Among the participants, $0.5 \%$ was Asian or Pacific Islander, $18.2 \%$ were African American, $8.1 \%$ were Hispanic, $1 \%$ was Native American or Alaskan Native, $69.4 \%$ were Caucasian, $0.8 \%$ were Middle Eastern or Arab, and $2.1 \%$ were of another race. Regarding income, 58\% reported an income between $\$ 0$ and $\$ 10,000$, 
$14.9 \%$ between $\$ 10,000$ and $\$ 20,000,5.2 \%$ between $\$ 20,000$ and $\$ 30,000,3.9 \%$ between $\$ 30,000$ and $\$ 40,000,1.3 \%$ between $\$ 40,000$ and $\$ 50,000$, and $2.9 \%$ reported and income of above $\$ 50,000$. In relation to the participants' highest education level attained, .8\% had less than a high school education, $12.7 \%$ were high school graduates or had a General Education Development (GED) equivalency, .5\% had trade/technical/vocational training, $70.1 \%$ had obtained some college, $11.9 \%$ were college graduates, $2.3 \%$ had completed some post-graduate work, and $2.1 \%$ had a post-graduate degree. Concerning geographic region in which the participants reside, $4.4 \%$ reported Northeast U.S., 38.8\% reported Southeast U.S., 19\% reported Midwest U.S., 1.6\% reported Northwest U.S., and 36.2\% reported Southwest U.S. Regarding the participants' current relationship status, $8.6 \%$ were living with a romantic partner, $51.2 \%$ were single, and $40.3 \%$ were in a committed relationship but were not living with their romantic partner (i.e., a dating relationship).

\section{Procedure}

After institutional review board approval was granted, participants completed an online survey created with Qualtrics survey software. The survey was primarily distributed across college/university campuses and through professional electronic mailing lists. Informed consent was obtained online, and participants could only gain access to the survey after consent was given. The survey consisted of questions pertaining to participant demographics, attitudes toward various romantic relationships, and the ideal age and timing of marriage.

\section{Measures}

\section{General demographics}

General demographics such as age, sex, and ethnicity were obtained from survey results. Due to the large proportion of Caucasian participants, ethnicity was constructed as a dichotomous variable for analysis purposes $(0=$ all other, $1=$ Caucasian). Age pertaining to those selected from the larger sample for this study was measured in 3 categories, where $1=$ $18-20(n=162), 2=21-22(n=164)$, and $3=23-25(n=$ 59). A dichotomous variable was also created for parents' relationship status (married $=0$, other $=1$ ) for analysis purposes. Participant current relationship status was also used as a predictor in the analysis.

\section{Religiosity}

Religiosity was measured utilizing five survey items that were summed for analysis purposes. The religiosity measure was patterned after previous studies utilizing the marital horizon framework (e.g., Willoughby, 2012), including measures of religious belief and practice (e.g., frequency of prayer and attendance of religious services). As an example item: My religious beliefs often greatly influence many of my daily decisions $(\alpha=.88)$.

\section{Background SES}

Background SES was measured utilizing three items assessing household income of the family of origin and the highest educational level obtained by one's father and one's mother. Internal consistency for this measure was fair $(\alpha=$ $.60)$.

\section{Current SES}

Current SES was measured utilizing two items separately: current income and highest level of education obtained.

\section{Marital timing}

Four items were utilized separately (as dependent variables) to measure the perceived ideal age and timing for marriage. These are listed below:

1. In your opinion, what age do you think is too young for someone to get married? (Measured on a 10point scale: $1=$ under 17 to $10=$ under 40 )

2. In general, at what age to you think people start getting "set in their ways" and may have more difficulty in marriage? (Measured on a 13-point scale: $1=17-19$ to $13=$ over 40 )

3. In your opinion, what is the ideal age for someone to get married? (Measured on a 7-point scale: $1=$ $18-20$ to $7=34$ years or older)

4. In your opinion, what is the ideal time for someone to get married? (Measured on a 5-point scale, with 1 = before college, 2 = during college, $3=$ after graduation, $4=$ only after starting your career, and $5=$ only after being established in your career)

\section{Analyses}

First bivariate correlations and descriptive statistics were reviewed (see Table 1). Following descriptive analysis, four separate multiple regression analyses were conducted regressing each dependent variable of marital timing on the predictor set (age, sex, ethnicity, background SES, parents' relationship status, current relationship status, current income, current education, and religiosity). Multiple regression was chosen as an ideal technique to investigate the research questions of this study as each predictor in the regression model can be compared with all other predictors in the model (and controlling for all other predictors in the model) (Pedhazur, 1997). For all multiple regression results, see Tables 2 and 3. All analyses were performed using PASW 21.0 (IBM Corp., 2012). 
Table 1: Independent Variable Mean, Standard Deviations, and Bivariate Correlations

\begin{tabular}{|c|c|c|c|c|c|c|c|c|c|c|c|}
\hline Variable & Mean & SD & 1 & 2 & 3 & 4 & 5 & 6 & 7 & 8 & 9 \\
\hline 1-Age & 1.73 & 0.71 & 1 & -.08 & $.38 * * * *$ & $.20 * * * *$ & -.07 & -.00 & .02 & -.03 & $-.17 * * *$ \\
\hline 2-Sex & 1.85 & 0.36 & -.08 & 1 & -.04 & -.08 & .03 & .08 & -.03 & $-.06^{*}$ & -.02 \\
\hline $\begin{array}{l}\text { 3- Current } \\
\text { Education }\end{array}$ & 3.96 & .98 & $.38 * * * *$ & -.04 & 1 & $.15^{* *}$ & .06 & .07 & $.22 *$ & $-.12 * * *$ & -.07 \\
\hline $\begin{array}{l}\text { 4-Current } \\
\text { Income }\end{array}$ & 2.16 & .08 & $.20 * * * *$ & -.08 & $.15^{* *}$ & 1 & .03 & $-.12 *$ & .06 & .05 & $-.16^{* * *}$ \\
\hline $\begin{array}{l}\text { 5- Back. } \\
\text { SES }\end{array}$ & 16.1 & 4.78 & -.07 & .03 & .06 & -.03 & 1 & -.03 & $.38 * * * *$ & $-.31 * * * *$ & .08 \\
\hline $\begin{array}{l}\text { 6- } \\
\text { Religiosity }\end{array}$ & 25.80 & 8.66 & .002 & .08 & .07 & $-.12 *$ & -.03 & 1 & -.05 & $-.14 * *$ & $.15^{* * *}$ \\
\hline 7-Ethnicity & 1.70 & 0.46 & .02 & -.03 & $.22 *$ & .06 & $.38 * * * *$ & -.05 & 1 & $-.16^{* *}$ & .00 \\
\hline $\begin{array}{l}\text { 8- Parent } \\
\text { Rel. Status } \\
\end{array}$ & 1.42 & 0.50 & -.03 & -.06 & $-.15^{*}$ & .05 & $-.31 * * * *$ & $-.14 * *$ & $-.16^{* *}$ & 1 & -.03 \\
\hline $\begin{array}{l}\text { 9- Rel. } \\
\text { Status }\end{array}$ & 6.23 & .83 & $-.17 * * * *$ & -.02 & -.07 & $-.16 * * *$ & .08 & $.15 * *$ & .00 & -.03 & 1 \\
\hline
\end{tabular}

Table 2: Summary of Regression Analyses for Variables Predicting Age Too Young to Marry and Age People Get "Set in Their Ways" $(\mathrm{N}=385)$

\begin{tabular}{|c|c|c|c|c|}
\hline \multirow[b]{2}{*}{ Variable } & \multicolumn{2}{|c|}{ Age too young to marry } & \multicolumn{2}{|c|}{$\begin{array}{l}\text { Age people get } \\
\text { "set in their ways" }\end{array}$} \\
\hline & $B$ & $S E B$ & $B$ & $S E B$ \\
\hline Sex & .30 & .18 & .53 & .48 \\
\hline Age & .02 & .10 & -.01 & .27 \\
\hline Ethnicity & .13 & .16 & -.09 & .42 \\
\hline Back. SES & -.01 & .02 & $.10 * *$ & .04 \\
\hline Parent Rel. Status & .21 & .14 & .11 & .38 \\
\hline Rel. Status & -.05 & .08 & -.13 & .22 \\
\hline Curr. Income & .03 & .03 & -.03 & .09 \\
\hline Curr. Education & .13 & .07 & .17 & .20 \\
\hline Religiosity & $-.03 * * * *$ & .01 & .01 & .02 \\
\hline$R^{2}$ & & .27 & & .03 \\
\hline $\boldsymbol{F}$ & & $3.07 * * *$ & & 1.13 \\
\hline
\end{tabular}

$* p<.05 . * * p<.01 . * * * p<.001 * * * * p<.0001$ 
Table 3: Summary of Regression Analyses for Variables Predicting Ideal Age to Marry and Ideal Time to Marry $(\mathrm{N}=385)$

\begin{tabular}{lllll}
\hline & \multicolumn{2}{c}{ Ideal age to marry } & Ideal time to marry \\
\hline Variable & $B$ & $S E B$ & $B$ & $S E B$ \\
Sex & -.10 & .09 & -.04 & .11 \\
Age & $.23 * * * *$ & .10 & .06 & .06 \\
Ethnicity & $-.39 * * * *$ & .08 & $-.46 * * *$ & .10 \\
Back. SES & .01 & .01 & .00 & .01 \\
Parent Rel. Status & $.20 * *$ & .07 & .04 & .09 \\
Rel. Status & -.06 & .04 & .09 & .05 \\
Curr. Income & -.02 & .02 & -.01 & .02 \\
Curr. Education & $.12 * *$ & .04 & -.03 & .05 \\
Religiosity & $-.02 * * * *$ & .00 & $-.02 * * * *$ & .01 \\
$\boldsymbol{R}^{2}$ & & .24 & & .12 \\
$\boldsymbol{F}$ & & $12.65 * * * *$ & & $5.18 * * * *$ \\
& & & &
\end{tabular}

\section{Results}

Research Question One: Predicting Perceived Age Too Young to Marry

In the multiple regression analysis predicting perceived age too young to marry, only religiosity had a significant association $(\beta=-.19 ; p<.0001)$. The predictor set accounted for $7.2 \%$ of the variance in perceived age too young to marry, $F(9,356)=4.65, p<.001, R^{2}=.072$.

Research Question Two: Predicting Perceived Ideal Age to Marry

In the multiple regression analysis predicting perceived ideal age to marry, age $(\beta=.22 ; p<.0001)$, ethnicity $(\beta=-.25 ; p<.0001)$, parents' marital status $(\beta=.13 ; p=$ $.007)$, current education $(\beta=.16 ; p=.002)$, and religiosity $(\beta$ $=-.28 ; p<.0001)$ had a significant association. The predictor set accounted for $24.2 \%$ of the variance in perceived ideal age to marry, $F(9,357)=12.65, p<.0001, R^{2}=.242$.

\section{Research Question Three: Predicting Perceived Ideal Time to} Marry

In the multiple regression analysis predicting perceived ideal time to marry, ethnicity $(\beta=-.26 ; p<.0001)$ and religiosity $(\beta=-.21 ; p<.0001)$ had a significant association. The predictor set accounted for $11.6 \%$ of the variance in perceived ideal time to marry, $F(9,355)=5.18, p<.0001$, $R^{2}=.116$.

Research Question Four: Predicting Perceived Age One Becomes "Set in Their Ways" and May Have More Difficulty in Marriage

In the multiple regression analysis predicting perceived age one becomes "set in their ways" and may have more difficulty in marriage, only family background SES $(\beta=.15$; $p=.012$ ) had a significant association. The predictor set accounted for $2.8 \%$ of the variance in perceived age one becomes 'set in their ways', $F(9,356)=1.13, p=.343$, $R^{2}=.028$.

\section{Discussion}

This study sought to expand upon the current literature by examining how several demographic and socioeconomic factors are associated with four measures of perceived marital timing in a sample of young adults. Marital horizon theory (Carroll et al., 2007) was used as a lens for this study, as one important component of this theory has to do with how the ideal age for marriage may shape risk-taking behaviors in young adults. Several results from the current study merit discussion.

\section{Convergent Findings}

In several ways, results of this study support those of previous studies. Our results show that ethnicity had a significant association with both perceived ideal age and timing for marriage, in that Caucasian participants reported a younger ideal age to marry and earlier ideal time to marry than other ethnic groups. This supports previous results showing Caucasians often enter earlier into marriage than other groups (e.g., Teachman, et al., 1987; Uecker \& Stokes, 2008). Additionally, our results show that parents' marital status had a significant association with perceived ideal age to marry, where those whose parents were divorced reported an older ideal perceived age to marry than those whose parents were not divorced. This supports previous work that has shown an association between parents' marital status and age at marriage (e.g., Keith \& Finlay, 1988).

Findings of the current study also show that education level was positively associated with perceived ideal age to marry. This finding is consistent with developmental life course theories incorporating the period of "emerging adulthood," as emerging adults in their 20s may be more involved in exploring educational and career pursuits rather than settling into marriage and family life (Arnett, 2004, 2007). This finding is also consistent with trend reports over the past 25 years showing that, in particular, women with a college education may be more likely to marry than those with lesser education, and tend to do so at a later age (Goldstein \& Kenney, 2001; Hymowitz, Carroll, Wilcox, \& 
Kaye, 2013). Hymowitz and colleagues (2013), reporting data from the American Community Survey, show that women who marry later (later 20s-early 30s) report greater personal and household income than those who marry at earlier ages. This is important point to take into account considering the sample of this study is $85 \%$ female and primarily those with "some college" as the highest level of education obtained.

The results of the current study also show that age was positively associated with ideal age to marry. Simply looking at mean values for our perceived ideal time to marry variable, the young adults in this sample perceive the ideal age to marry in the 23-25 age category. This supports the results by Carroll et al. (2007) who found that young adults indicated the ideal age to marry as approximately 25 , and the older the young adult, the older the ideal age to marry (particularly for women).

The results of this study specifically highlight the pervasive impact of religiosity on perceived marital timing. For the young adults in this sample, religiosity tended to be an important influence on the perception of this particular marital horizon. Our results show a negative association between religiosity with perceived age too young to marry, ideal age to marry, and ideal time to marry. These results both support and expand upon previous work showing that those higher in religiosity enter into marriage earlier than those who are not religious (Uecker \& Stokes, 2008), and that religious factors often play a role when considering marriage (Sigalow et al., 2012).

\section{Divergent Findings}

Perhaps what is most divergent about the results of this study is what we did not find. In most of the dependent measures of marital timing (perceived age too young to marry, ideal age to marry, and ideal time to marry) we did not find any significant associations with background SES. This is contrary to results of previous studies that have found connections between parents' education and financial assets and age at marriage (e.g., Axinn \& Thornton, 1992; Uecker \& Stokes, 2008). This may have to do with the age group of the sample. Perhaps some young adults, and particularly more educated young adults (as may be represented by the higher overall education levels in the sample of this study), may be more influenced by their own current situation (education experience and peer group influences) rather than background factors pertaining to attitudes toward marital timing.

Interestingly, the only significant association with background SES was the positive association found with the perceived age people start getting set in their ways and may have more difficulty in marriage. Perhaps higher family background SES influences may underscore the limited importance of marrying early, and that the potential risks of marrying at an older age are minimal. However, since the "age set in ways" phenomenon remains under investigated, this result is difficult to compare with those of previous studies.

\section{Implications and Future Directions \\ Implications for practitioners}

Professionals who work with couples and families could potentially use the results of this study in several ways. These professionals could include, but are not limited to, Licensed Marriage and Family Therapists, Licensed Clinical Social Workers, Licensed Professional Counselors, Family Life Educators, and other community service providers. Understanding how or when people get married and the influences behind making decisions in relationships will help professionals who work with couples and families by providing a framework for assessing how attitudes toward relationships and marital timing are shaped. This may help professionals understand relationship formation with greater specificity and accuracy. Also, taking into account how attitudes toward marriage and martial timing are shaped by a variety of factors is an important part of creating educational programming and interventions patterned around the needs of the target audience (e.g., Duncan \& Goddard, 2011). The results of this study may prompt professionals to think of the multitude of variables that play into marital timing for young adults, including those mentioned in the current study.

The results of this study particularly highlight implications for those who work with couples and families in religious settings. Our findings show that those young adults higher in religiosity perceive a younger ideal age to marry and earlier ideal time to marry. As previously mentioned in this paper, younger age at marriage and lower educational achievement have been identified as risk factors for divorce. However, religiosity has also been identified as a protective factor in marriage, positively associated with marital satisfaction and stability (Bramlett \& Mosher, 2002; Sullivan, 2001).

Research has identified that upwards of $75 \%$ of marriages take place in religious settings in the U.S. (Stanley, Amato, Johnson, \& Markman, 2006). Religious settings may represent an important avenue to educate young people about romantic relationships and marriage. Research has also shown that premarital education can reduce the odds for divorce and boost marital satisfaction and communication skills (Carroll \& Doherty, 2003; Fawcett, Hawkins, Blanchard, \& Carroll, 2010). In a random household phone survey, Stanley and colleagues (2006) found that $93 \%$ of couples who reported receiving premarital education did so in a religious setting. Stanley et al. (2001) found that clergy and lay leaders implementing premarital education were just as effective as university staff with advanced degrees. Thus clergy and other lay leaders working in religious settings can be an effective resource for young adults to increase relationship skills (Stanley et al., 2001), ponder the impact of relationship decisions (Manning \& Smock, 2005; Stanley, Rhoades, \& Markman, 2006), and marital roles (Kuperberg, 2014), but also connect to religious beliefs and practices which can aid in problem solving and conflict resolution in marriage (Lambert \& Dollahite, 2006). 


\section{Implications for Researchers}

More research is needed to explore the ongoing connection between changing young adult attitudes toward marriage with marital processes and marital outcomes. More research is needed to conceptualize marital timing beyond simply a focus on age at marriage. Further research should investigate how various aspects of marital timing are associated with later behavioral outcomes in young adults. Researchers can benefit from further utilization of theoretical models such as marital horizon theory that offer broader conceptualizations of perceptions of marriage.

The results of this study show that religiosity may particularly influence various perceptions of marital timing and marital horizons in young adults. Yet further work is needed to replicate the findings of this study. More specifically, a more diverse sample is needed to ensure more generalizable results. Further research should seek to study samples with more variation in educational level, gender, ethnicity, and religiosity.

\section{Limitations and Conclusions}

This study contains some important limitations of which the reader should be aware. The analyses conducted are crosssectional and cannot comment on causation. Also, the sample is largely made up of individuals in college, and the results may be less useful to individuals who have a different educational level. This is important to consider since those in more disadvantaged circumstances are often at greater risk for marital disruption. In addition, the disproportionate presence of females in the sample is another area to take into consideration. Also, the sample was primarily drawn from those living in southern states (75\%), and southern states tend to be higher in religiosity than other states (Gallup, 2014). For the sample of the current study, $75.5 \%$ reported they were either "moderately religious" or "very religious." Future research should seek to replicate the findings of this study with more geographically and religiously diverse samples.

In conclusion, this study explored the association between demographic, socioeconomic, and religiosity factors with various measures of perceived ideal timing in a sample of young adults. Although some results were supportive of previous literature, the focus and results of this study adds to previous work by exploring associations with multiple aspects of marital timing rather than simply a focus on ideal marital age. Utilizing the marital horizon framework can help researchers and practitioners better conceptualize how young adults' marital attitudes are formed and how they make decisions about relationships as well as the impact of these decisions. The results of this study lay the groundwork for further investigation and may be of use to those who work with couples in various settings to construct more comprehensive educational and therapeutic efforts to better support healthy relationship development.

\section{References}

Amato, P. R. (2010). Research on divorce: Continuing trends and new developments. Journal of Marriage and Family, $72,650-666$.

Amato, P. R. (1996). Explaining the intergenerational transmission of divorce. Journal of Marriage and Family. $58,628-640$.

Ammons, S., \& Edgell, P. (2007). Religious influences on work-family tradeoffs. Journal of Family Issues, 28, 794-826.

Arnett, J. (2004). Emerging adulthood. New York, NY: Oxford University Press.

Arnett, J. (2007). Emerging adulthood: What is it, and what is it good for? Child Development Perspectives, 1, 6973.

Axinn, W. G., \& Thornton, A. (1992). The influence of parental resources on the transition to marriage. Social Science Research, 21, 261-285.

Beal, S. J., \& Crockett, L. J. (2012). The life course in the making: Gender and the development of adolescents' expected timing of adult role transitions. Developmental Psychology, 48(6), 1727-1738.

Booth, A., \& Edwards, J. N. (1985). Age at marriage and marital instability. Journal of Marriage and the Family, 47, 67-75. doi:10.2307/352069

Bramlett, M. D., \& Mosher, W. D. (2002). Cohabitation, marriage, divorce, and remarriage in the United States (Vital and Health Statistics, Series 23, No. 22). Hyattsville, MD: National Center for Health Statistics.

Carroll, J. S., Badger, S., Willoughby, B. J., Nelson, L. J., Madsen, S., \& Barry, C. M. (2009). Ready or not? Criteria for marriage readiness among emerging adults. Journal of Adolescent Research, 24, 349-375.

Carroll, J. S., \& Doherty, W. J. (2003). Evaluating the effectiveness of premarital prevention programs: A metaanalytic review of outcome research. Family Relations, 52, 105-118.

Carroll, J. S., Hill, L. M., Vitas, J. M., \& Willoughby, B. J. (2012). "When are you getting married?" The intergenerational transmission of attitudes regarding marital timing and marital importance. Journal of Family Issues, 33(2), 223-245. doi:10.1177/0192513X11408695

Carroll, J. S., Willoughby, B., Badger, S., Nelson, L. J., Barry, C. M., \& Madsen, S. (2007). So close, yet so far away: The impact of varying marital horizons on emerging adulthood. Journal of Adolescence Research, 22(3), 219247.

Cherlin, A. (2009). The marriage-go-round: The state of marriage and family in America today. New York, NY: Vintage Books.

Cohn, D., Passel, J., Wang, W., Livingston, G. (2011, December 14). Barely half of U.S. adults are married-A record low. Pew Research Center: Social Trends. Retrieved from http://www.pewsocialtrends.org/2011/12/14/barelyhalf-of-u-s-adults-are-married-a-record-low/

Copen, C. E., Daniels, K., \& Mosher, W. D. (2013, April 4). First premarital cohabitation in the United States: 20062010 National Survey of Family Growth. National Health Statistics Reports. Retrieved from http://www.cdc.gov/nchs/data/nhsr/nhsr064.pdf 
Copen, C. E., Daniels, K., Vespa, J., \& Mosher, W. D. (2012, March 22). First marriages in the United States: Data from the 2006-2010 National Survey of Family Growth. National Health Statistics Reports, 49. Retrieved from http://www.cdc.gov/nchs/data/nhsr/nhsr049.pdf

DeGenova, M. K., Stinnett, N., \& Stinnett, N. (2011). Intimate relationships, marriages and families $\left(8^{\text {th }} \mathrm{ed}\right.$.). New York: McGraw Hill.

Duncan, S. F. \& Goddard, H. W. (2011). Family life education: Principles and practices for effective outreach. Thousand Oaks, CA: Sage.

Ellison, C. G., Burdette, A. M., \& Glenn, N. D. (2011). Praying for Mr. Right? Religion, family background, and marital expectations among college women. Journal of Family Issues, 32, 906-931.

Fawcett, E. B., Hawkins, A. J., Blanchard, V. L., \& Carroll, J. S. (2010). Do premarital programs really work? A metaanalytic study. Family Relations, 59, 232-239.

Gallup (2014, February 3). Mississippi most religious state, Vermont least religious. Retrieved from http://www.gallup.com/poll/167267/mississippi-religiousvermont-least-religious-state.aspx

Glenn, N., Uecker, J., \& Love, R. (2010). Later first marriage and marital success. Social Science Research, 39 (5), 787 800.

Glick, J. E., Ruf, S. D., White, M. J., \& Goldscheider, F. (2006). Educational engagement and early family formation: Differences by ethnicity and generation. Social Forces, 84, 1391-1415.

Goldstein, J. \& Kenney, C. (2001) Marriage delayed or marriage forgone? New cohort forecasts of first marriage for U.S. women. American Sociological Review, 66 (4), 506-519.

Heaton, T. B. (1991). Time-related determinants of marital dissolution. Journal of Marriage and the Family, 53, 285295. doi:10.2307/352899

Holman, T. (2001). Premarital prediction of marital quality or breakup: Research, theory, and practice. New York, NY: Kluwer Academic/Plenum.

Hymowitz, K., Carroll, J. S., Wilcox, W. B., \& Kaye, K. (2013). Knot yet: The benefits and costs of delayed marriage in America. Washington, DC: The National Campaign to Prevent Teen and Unplanned Pregnancy.

IBM Corp. (Released 2012). IBM SPSS Statistics for Windows, Version 21.0. Armonk, NY: IBM Corp.

Keith, V. M., \& Finlay, B. (1988). The impact of parental divorce on children's educational attainment, marital timing, and likelihood of divorce. Journal of Marriage and Family, 50, 797-809.

Koball, H. (1998). Have African American men become less committed to marriage? Explaining the twentieth century racial cross-over in men's marriage timing. Demography, 35(2), 251-258.

Krogstad, Jens Manuel (2014, April 30). 5 facts about the modern American family. Pew Research Center: Fact Tank. Retrieved from http://www.pewresearch.org/fact$\operatorname{tank} / 2014 / 04 / 30 / 5$-facts-about-the-modern-americanfamily/

Kuperberg, A. (2014), Age at coresidence, premarital cohabitation, and marriage dissolution: 1985-2009. Journal of Marriage and Family, 76, 352-369. doi: 10.1111/jomf.12092
Lee, G. R. (1977). Age at marriage and marital satisfaction: A multivariate analysis with implications for marital stability. Journal of Marriage and the Family, 39, 493-504. doi: $10.2307 / 350904$

Lambert, N. M., \& Dollahite, D. C. (2006). How religiosity helps couples prevent, resolve, and overcome martial conflict. Family Relations, 55, 439-449.

MacInnes, M. D. (2011). Altar-bound? The effect of disability on the hazard of entry into a first marriage. International Journal of Sociology, 41(1), 87-103. doi:10.2753/IJS00207659410105

Manning, W. D., \& Smock, P. J. (2005). Measuring and modeling cohabitation: New perspectives from qualitative data. Journal of Marriage and Family, 67, 989-1002.

Oppenheimer, V. K., Kalmijn, M., \& Lim, N. (1997). Men's career development and marriage timing. Demography, 34(3), 311-330. doi:10.2307/3038286

Payne, K. K. (2011). Sequencing of family experiences (FP11-11). National Center for Family \& Marriage Research. Retrieved from http://ncfmr.bgsu.edu/pdf/family_profiles/file102409.pdf

Pedhazur, E. J. (1997). Multiple regression in behavioral research: Explanation and prediction $\left(3^{\text {rd }}\right.$ ed). New York, NY: Thomson Learning.

Raley, R. K. (2000). Recent trends in marriage and cohabitation: The United States. In L.Waite, C. Bachrach, M. Hindin, E. Thomson, \& A, Thornton (Eds), Ties that bind: Perspectives on marriage and cohabitation (pp. 1939). Hawthorne, CA: Aldine de Gruyter.

Raley, R. K., \& Bumpass, L. (2003). The topography of the divorce plateau: Levels and trends in union stability in the United States after 1980. Demographic Research, 8, 245260. doi:10.4054/DemRes.2003.8.8

Regnerus, M. (2009, April 26). Freedom to marry young. The Washington Post. Retrieved from http://www.washingtonpost.com/wpdyn/content/article/2009/04/24/AR2009042402122.html

Scott, M. E., Schelar, E., Manlove, J., \& Cui, C. (2009). Young adult attitudes about relationships and marriage: Times may have changed but expectations remain high. Child Trends Research Brief. Retrieved from http://www.childtrends.org/Files/Child_Trends2009_07_08_RB_YoungAdultAttitudes.pdf.

Sigalow, E., Shain, M., \& Bergey, M. R. (2012). Religion and decisions about marriage, residence, occupation, and children. Journal for the Scientific Study of Religion, 51(2), 304-323. doi:10.1111/j.1468-5906.2012.01641.x

Stanley, S. M., Makman, H. J., Prado, L. M., Olmos-Gallo, A., Tonelli, L., St. Peters, M., Whitton, S. W. (2001). Community-based premarital prevention: Clergy and lay leaders on the front lines. Family Relations, 50, 67-76.

Stanley, S. M., Amato, P. R., Johnson, C. A., \& Markman, H. J. (2006). Premarital education, marital quality, and marital stability: Findings from a large, random, household survey. Journal of Family Psychology, 20, 117-126.

Stanley, S. M., Rhoades, G. K., \& Markman, H. J. (2006). Sliding versus deciding: Inertia and the premarital cohabitation effect. Family Relations, 55, 499-509.

Sullivan, K. T. (2001). Understanding the relationship between religiosity and marriage: An investigation of the immediate and longitudinal effects of religiosity on 
newlywed couples. Journal of Family Psychology, 15, 610626.

Teachman, J. D., Polonko, K. A., \& Leigh, G. K (1987). Marital timing: Race and sex comparisons. Social Forces, 66, 239-268.

Teachman, J. D., Tedrow, L. M., \& Crowder, K. D. (2000). The changing demography of America's families. Journal of Marriage and the Family, 62, 1234-1246.

Uecker, J. E., \& Stokes, C. E. (2008). Early marriage in the United States. Journal of Marriage and Family, 70, 835846. doi: 10.1111/j1741-3737.2008.00539x.

Willoughby, B. J. (2012). Associations between sexual behavior, sexual attitudes, and marital horizons during emerging adulthood. Journal of Adult Development, 19(2), 100-110.

Willoughby, B. J., Carroll, J. S., Vitas, J. M., \& Hill, L. M. (2012). "When are you getting married?" The intergenerational transmission of attitudes regarding marital timing and marital importance. Journal of Family Issues, $33,223-245$. 